Journal of Economics and Behavioral Studies

Vol. 5, No. 4, pp. 210-220, April 2013 (ISSN: 2220-6140)

\title{
The Proposed Banning of Alcohol Advertising in a Developing Economy
}

\author{
Jeevarathnam Parthasarathy Govender \\ Durban University of Technology, Durban, South Africa \\ govendej@dut.ac.za
}

\begin{abstract}
The growing problem of alcohol misuse and its social consequences have been attributed to the advertising of alcohol, by some parties. Alcohol companies and the advertising industry have refuted this claim. It is against this background that this paper seeks to assess consumer attitudes towards alcohol advertising in South Africa. A survey was conducted amongst a sample of 400 respondents. Respondent demographics and attitudes towards the advertising of alcohol were ascertained. The results indicate no significant relationship between the selected demographic variables (viz. gender, age, income, education level and race) and attitude towards the advertising of alcohol. Some perspectives on the implications for policy and practice are presented.
\end{abstract}

Keywords: Alcohol advertising, alcohol abuse, alcohol misuse, counter-advertising of alcohol

\section{Introduction}

The recent proposed banning of alcohol advertisements by the South African government has been greeted with mixed reaction. Adherents to the banning have argued that alcohol advertising has resulted in the many social ills associated with alcohol misuse, while proponents believe that alcohol misuse pertains to a small number of individuals and that this behaviour is not as a result of the advertising of alcohol.According to the World Health Organization (WHO), although between $50 \%$ and $67 \%$ of South Africans do not consume alcohol, South African drinkers are the fifth heaviest consumers of alcohol in the world, with an average of 35 liters of pure alcohol per annum. This is twice as much as in France or the USA (The Economist, 2012). According to Haw (2011), at face value, the primary objective of advertising is, fundamentally, to increase sales, and when more alcohol is sold, the incidences of abuse are likely to increase. Studies by the World Health Organization (WHO) indicate that advertising for alcohol does not only influence brand choice among young people but has wider marketing implications, potentially linked to alcohol abuse (Parry, Burnhams \& London, 2012). Several overseas countries restrict advertising related to alcohol e.g. France restricts the content of radio and print advertisements to specific aspects such as product name, ingredients, alcohol strengths, method of production, and conditions of sale, with a further requirement of moderation in the advertising message. Norway and Sweden prohibit advertising to the public of alcohol beverages over 2.5\% and 3.5\% by volume respectively (Institute of Alcohol Studies, 2007). On the other hand, research conducted in the wine industry in South Africa indicates that advertising plays a minor role in influencing drinking choices leading to the conclusion that the banning of alcohol advertising would not have an impact on the abuse of alcohol. It is contended that since many people who abuse alcohol are not influenced by brands, then the banning of alcohol advertising will not really address the issue of alcohol abuse (Haw, 2011).

The liquor industry believes that drinking patterns in South Africa are normal and that the problem of abuse lies with a minority of individuals who abuse alcohol, and suggests that the solution lies in changing the behavior of abusers of alcohol through education (Parry, Burnhams \& London, 2012). This paper therefore aims to assess consumer attitude towards alcohol advertising in South Africa. The demographic profile of respondents is ascertained, specific aspects on attitudes towards the banning of alcohol advertising are examined and the relationship between the selected biographic variables and attitude towards the banning of alcohol advertising are determined. This paper is guided by the following hypotheses:

Hypothesis 1: There is no significant relationship between gender and attitude towards alcohol advertising Hypothesis 2: There is no significant relationship between age and attitude towards alcohol advertising 
Hypothesis 3: There is no significant relationship between income and attitude towards alcohol advertising

Hypothesis 4: There is no significant relationship between education level and attitude towards alcohol advertising

Hypothesis 5: There is no significant relationship between race and attitude towards alcohol advertising

\section{Literature review}

The literature review addresses three fundamental areas associated with the banning of alcohol advertising viz. advertising as a promotional tool, the arguments in favor of the banning of alcohol advertising and the arguments in support of the advertising of alcohol.

Advertising as a promotional tool: Advertising, as a promotional tool, aims at informing, persuading and reminding the consumer. Informing aims to stimulate interest in the product, persuading is designed to stimulate an action (e.g. to start consuming or consume more of a product), and reminding aims to keep the product or brand name in the public's mind (McDaniel, Lamb \& Hair, 2012).This is supported by Etzel, Walker \& Stanton (2007) who state that advertising is intended to encourage the consumer to take some kind of action in the present or the future regarding a product. Shimp (2010) cites the case of Absolut Vodka, which entered the US market in the early 1980s, as an unknown brand. Advertising was permitted only in the print media. Using a sound advertising campaign, Absolut became the leading Vodka brand in the US by the early 2000s. A similar success story, pertaining to Guinness Beer in Africa is also cited, illustrating the effectiveness of advertising. Lamb, Hair, McDaniel, Boschoff \& Terblanche (2008) attribute the success of Black Label, the leading beer brand in South Africa, to advertising. Amen (2011) explains that consumer attitude is about belief, feeling and intention towards a product or brand and identifies a clear link between advertising and influencing consumer's attitudes. This view is reinforced by Schifman, Kanuk \& Wisenbilt (2010) who make reference to the "attitude-toward-the-ad" model which confirms that exposure to advertisements shapes consumer attitudes towards products. Shimp (2010) contends that advertising can be manipulative in the sense that consumers can be influenced to do things they would otherwise not do were it not for exposure to advertising. If this argument had to be extended to the extreme, the implication is that people are capable of moving against their free wills. This can be achieved through the use of subtlety and subliminal messages. An ethical issue that has been raised is that of advertising of alcohol products targeting economically disadvantaged consumers (Shimp, 2010). This is relevant in the context of South Africa, which has a large proportion of economically disadvantaged consumers dispersed throughout the country, both in urban and rural areas.

The argument in favor of the banning of alcohol advertising: Although advertising in South Africa is regulated by the Advertising Standards Authority (ASA), advertisements are permitted that link the products of alcohol companies to things that are not related with the properties of their products, but rather to notions such as financial success, sex, acceptance and even condemnation of people who buy small quantities of beer or people who drink milk instead of beer while watching sport (Parry, Burnhams \& London, 2012). Alcohol has been linked to South Africa's murder rate, which ranks among the highest in the world. $75 \%$ of knife murders, $50 \%$ of murders through "blunt instrument", and $40 \%$ of murders involving firearms are committed while under the influence of alcohol. 7000 road deaths in South Africa each year have been attributed to alcohol, with more than a third of those killed, being pedestrians, the majority of who are also drunk. Alcohol is also believed to be associated with the high HIV-infection rate, as people who are drunk tend not to engage in safe sex (The Economist, 2012).Proponents of the banning of alcohol advertising cite the South African experience on the banning of tobacco advertisements in the early 2000's showing a decrease in smoking rates. This concurs with the findings overseas, that in the long term, a total ban on tobacco advertising results in reduced consumption (Peer, Bradshaw, Laubsher \& Steyn, 2009). The argument is that this experience can be extended to alcohol advertising.

The argument in support of the advertising of alcohol: There appears, on the other hand, to be a justification for the advertising of alcohol. Moerdyk (2011) believes that total loss of marketing revenue, should there be a ban on alcohol advertising, would be R 2.6 billion with an associated Value Added Tax loss of R289 million. Over 30000 individuals will lose their breadwinners, considering that a large proportion of the 
workforce are employed in the lower ranks of the advertising industry, particularly in the print industry. Jogender (2008) indicates that the alcohol industry together with related industries make up a significant percentage of South Africa's GDP. According to Moerdyk (2011), the broader consequences of the banning of alcohol advertisements include the inability of television broadcasters to purchase sports programming from overseas due to diminished revenues, the inability to broadcast lifestyle and sports programming containing embedded alcohol sponsorship or branded content, and a diminished capability by South Africa to host international commercial and sport events should any of the events have international liquor companies as sponsors, as was the case of Budweiser in the 2010 FIFA Soccer World Cup. Ringold (2008) argues that advertising for alcohol plays an important role in product and brand differentiation, hence reducing consumer confusion. Advertising for alcohol helps consumers select between alternative brands, provide information, and facilitate the introduction of new products and brands. Alcohol advertising also encourages competitive pricing and encourages organizations to back product claims.

\section{Methodology}

Study type: The research constituted a quantitative and descriptive study. Houser (2008) defines descriptive research as a type of study that tries to find out what, why, who or where. The study used a cross-sectional methodology. Cross-sectional designs involve the collection of information from any given sample of population elements at approximately the same time (Welman, Kruger and Mitchell, 2009).

Population and sampling: Researchers usually draw conclusions about large groups of customers by studying a small sample of the total customer population. A sample is a segment of the population chosen for research to represent the population as a whole (Kotler \& Armstrong, 2010). The population comprised South African consumers over the age of 18 . To this end, a sample of 400 consumers was considered appropriate. The sample size was guided by Sekaran (2003) who suggests that for a population in excess of 1 million, a sample of 384 respondents was adequate to draw inferences. Non-probability sampling was used. According to Welman et al., (2009), non-probability sampling offers the advantage of being less complicated and more economical in terms of time and financial constraints. Using judgemental sampling, four major shopping malls in the city of Durban, South Africa were chosen. This was done with a view to attempting to ensure a fair representation of the demographic profile of consumers. 100 respondents were chosen at each shopping mall on the basis of convenience sampling.

Data collection: The questionnaire covered respondent demographics and attitudes towards the advertising of alcohol. Interval scaling was used. Measurement consisted of the use of a five-point Likert scale (strongly disagree $=1$; strongly agree $=5$ ). The end result was 390 usable questionnaires, a statistically acceptable sample size.

Procedure: The data was analysed using SPSS. The level of significance was set at $95 \%(\mathrm{p}=0.05) .18$ respondents did not indicate their race. This constituted $4.6 \%$ of the responses and was therefore considered negligible. The data was analysed both at a descriptive and inferential level.

\section{Results and Discussion}

Biographical profile of respondents: As illustrated in Table 1, it emerged that $62 \%$ of respondents were male and 38\% were female. The largest respondent group was from the 18 to 25 age category (30\%) followed by $23 \%$ of respondents being from the 26 to 33 age group and $20 \%$ being between 42 and 49 years of age. The largest group (22\%) earned between R13 000 and R16 000 a month, followed by 20\% of respondents who were in the R16 000 to R20 000 income category. 8\% of respondents earned less than R4 000, and 9\% earned a monthly income of more than R20 000 . The majority of respondents (52\%) had a tertiary education and $6 \%$ of respondents did not complete high school. Owing to the diversity of the South African population, it was considered appropriate to ascertain the racial classification of respondents. 18 respondents did not indicate their race group, possibly 
Table 1: Biographical profile of Respondents

\begin{tabular}{|c|c|}
\hline $\begin{array}{ll}\text { Respondents } & \mathrm{n}=\mathbf{3 9 0}\end{array}$ & $\%$ \\
\hline \multicolumn{2}{|l|}{ Gender } \\
\hline Male & 62 \\
\hline \multirow[t]{2}{*}{ Female } & 38 \\
\hline & 100 \\
\hline \multicolumn{2}{|l|}{ Age } \\
\hline $18-25$ & 30 \\
\hline $26-33$ & 23 \\
\hline $34-41$ & 10 \\
\hline $42-49$ & 20 \\
\hline Over 50 & 17 \\
\hline Total & 100 \\
\hline \multicolumn{2}{|l|}{ Monthly income (Rands) } \\
\hline$<4000$ & 8 \\
\hline $4000-7000$ & 10 \\
\hline 7 001-10 000 & 14 \\
\hline $10001-13000$ & 17 \\
\hline $13001-16000$ & 22 \\
\hline $16001-20000$ & 20 \\
\hline \multirow{2}{*}{ Over 20000} & 9 \\
\hline & 100 \\
\hline \multicolumn{2}{|l|}{ Education level } \\
\hline Tertiary qualification & 52 \\
\hline Matriculation & 42 \\
\hline \multirow[t]{2}{*}{ Below Matric } & 6 \\
\hline & 100 \\
\hline \multicolumn{2}{|l|}{ Race* } \\
\hline Asian & 28 \\
\hline Black & 26 \\
\hline Coloured & 12 \\
\hline \multirow[t]{2}{*}{ White } & 34 \\
\hline & 100 \\
\hline
\end{tabular}

* Based on 372 responses as 18 respondents did not indicate their racial classification.

Owing to the sensitive nature of the question. The non-response by $4.6 \%$ of respondents was considered negligible for statistical analysis.

Opinions on the advertising for alcohol: This section presents respondents opinions on the advertising of alcohol. The banning of alcohol advertising will reduce alcohol consumption. It emerged that the majority $(53.3 \%)$ of respondents disagreed (33.3\% strongly agreeing and $20 \%$ agreeing) that the banning of alcohol advertising will reduce alcohol consumption. $30 \%$ of respondents were in agreement $110 \%$ agreeing and $20 \%$ strongly agreeing) that the banning of alcohol advertising will reduce alcohol consumption. The results are illustrated in Figure 1. This finding is consistent with previous studies. Researchers point out that in Norway, for example, where advertising for alcoholic beverages is strictly prohibited, consumption has been rising steadily. Canada conducted several studies on alcohol advertising bans implemented in some provinces and found that in Manitoba, a ban spanning seven years did not result in a decrease in the sales of beer, but rather an increase (Haw, 2011). Precedents in Denmark and New Zealand found no evidence of a reduction in alcohol abuse, resulting in bans on advertising for alcohol being lifted (Fin24, 2011). According to (Moerdyk, 2011), in South Africa, alcohol abuse in poorer communities, where a large proportion of incidents occur, emanates mainly from non-branded liquor products such as home brews. 
Figure 1: Banning of alcohol advertising will reduce alcohol consumption

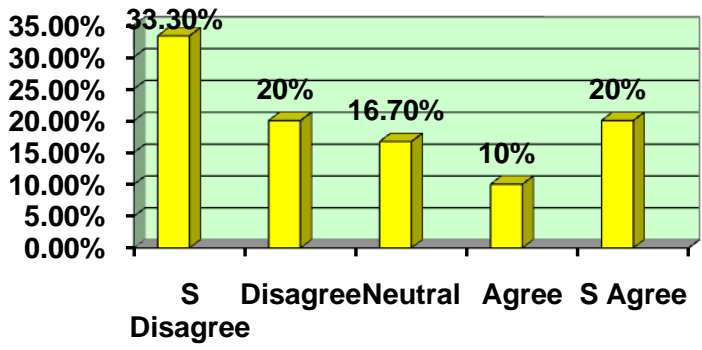

Alcohol advertisements influencing non-drinkers to consume alcohol

The results, as presented in Figure 2, reveal that the majority (50\%) of respondents believed that alcohol advertisements influence non-drinkers to consume alcohol (26.7\% strongly agreeing and $23.3 \%$ agreeing). $13 \%$ were neutral in this regard. This concurs with research by Anderson, de Bruijn, Angus Gordon \& Hastings (2009) which show that the advertising of alcohol influences young people's behavior, encourages alcohol consumption, creates positive beliefs about drinking, encourages young people to drink sooner and in greater quantities.

Figure 2: Alcohol advertisements influencing non-drinkers to consume alcohol

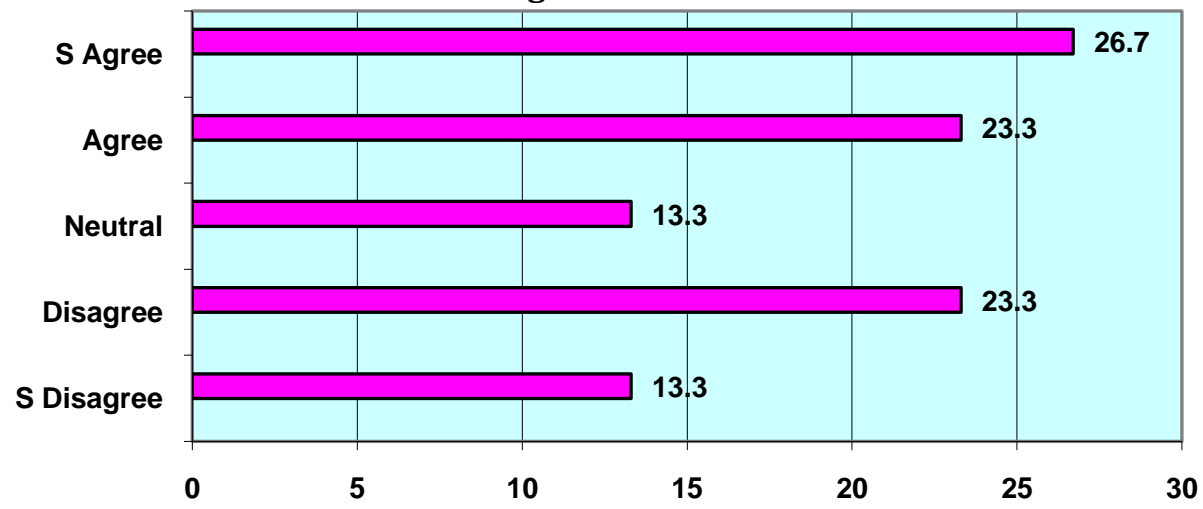

Alcohol advertisements influencing youth and adolescents to consume alcohol

The results, as reflected in Figure 3, indicate that $70 \%$ of respondents are in agreement that alcohol advertisements influence youth and adolescents to consume alcohol, with 33.3\% agreeing and 36.7\% strongly agreeing in this regard. $20 \%$ of respondents disagreed that alcohol advertisements influence youth and adolescents to consume alcohol. The findings among the majority of respondents are consistent with the view of Ukwazi (2012), that the proposed ban on alcohol advertising will stop making alcohol look fashionable and consequently avoid the targeted advertising reaching the vulnerable, including children.

Figure 3: Alcohol advertisements influencing youth and adolescents to consume alcohol

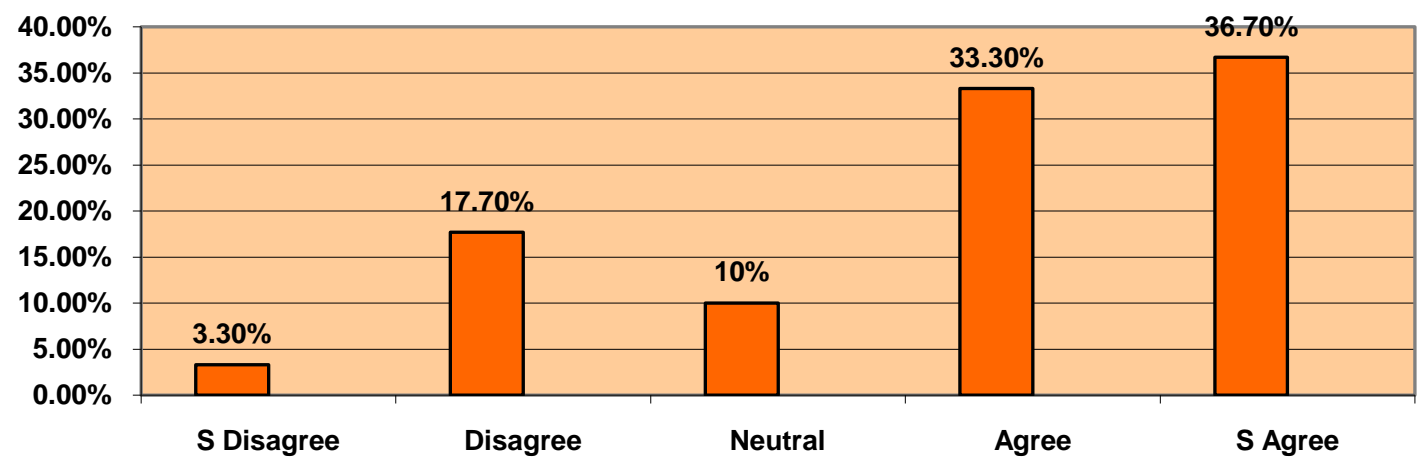

Advertisements for alcohol influencing people's view on alcohol positively 
It emerged that the majority (60.3\%) of respondents were in disagreement (33.3\% strongly disagreeing and $27 \%$ disagreeing) that advertisements for alcohol influenced people's view on alcohol positively. $30 \%$ of respondents agreed with this view. This is illustrated in Figure 4.This is consistent with the view of Shimp (2010) who argues that advertising can be manipulative, influencing consumers to do things they would otherwise not due in the absence of the advertising in question.

\section{Figure 4: Advertisements for alcohol influencing people's view on alcohol positively}

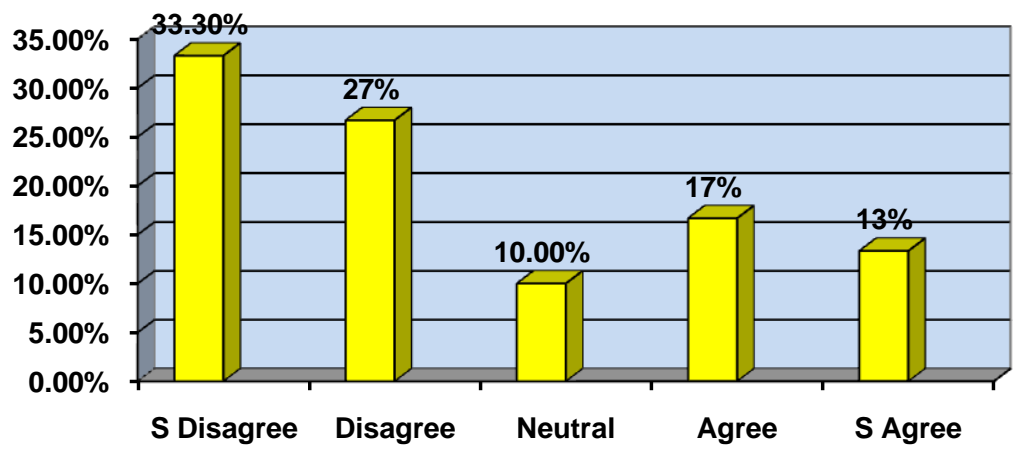

Excessive alcohol consumption being associated with serious health issues

The results, as presented in Table 5, indicate an overwhelming majority of respondents, at $97 \%$, being in agreement that excessive alcohol consumption results in serious health issues. None of the respondents disagreed that excessive alcohol consumption results in serious health issues. The majority view, that excessive alcohol consumption is associated with serious health issues, is supported by the WHO which ranks South Africa fourth out of five in terms of health risks associated with drinking patterns (Crotty, 2012). In addition, 130 people die daily, as a result of alcohol-related causes in South Africa (Parry, Burnhams \& London, 2012).

Figure 5: Excessive alcohol consumption being associated with serious health issues

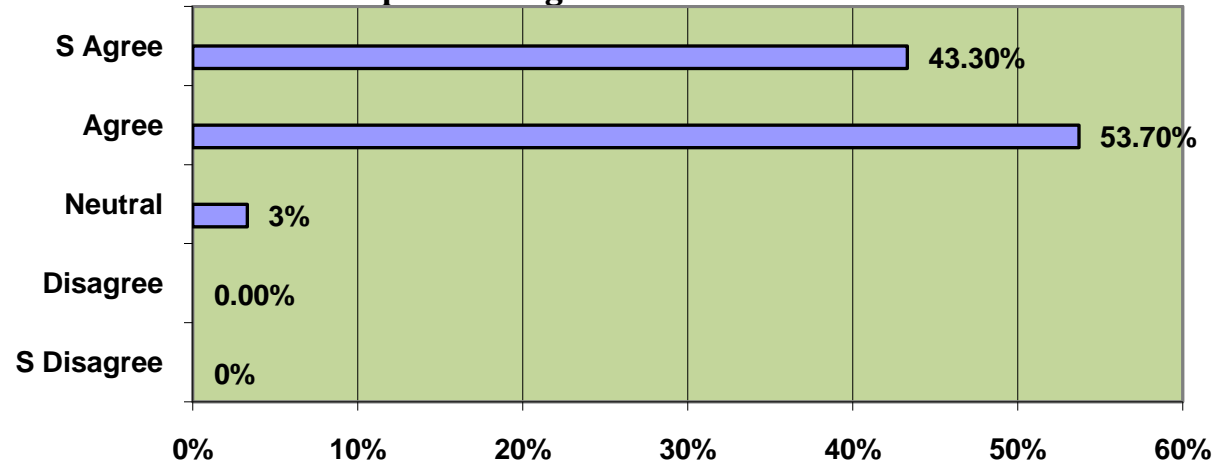

Alcohol advertisements should be completely banned

Although the majority of respondents believed that the banning of alcohol advertisements will not reduce alcohol consumption (a finding discussed earlier), 60\% of respondents believed that alcohol advertisements should be completely banned (20\% agreeing and $40 \%$ strongly agreeing). This is illustrated in Figure 6 . This finding is in agreement with Ross (2009), who states that experts see a definite link between alcohol advertising and the drinking habits, especially among young people, and have called for a ban on alcohol advertising. 
Figure 6: Alcohol advertisements should be completely banned

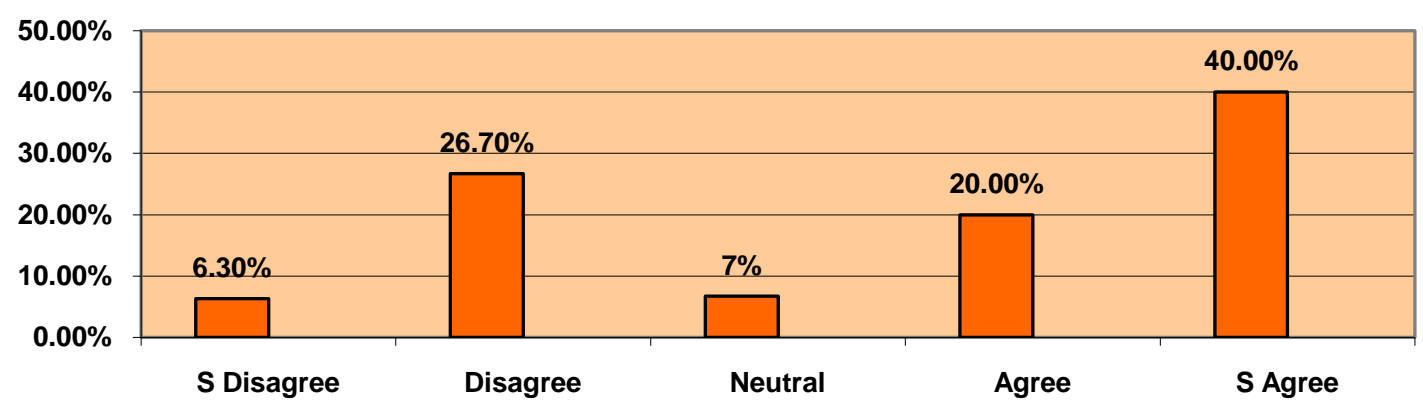

Sponsorships by alcohol companies should be prohibited

Interestingly, respondent opinion was not as strong when it came to sponsorship by alcohol companies, compared to advertising by alcohol companies as explained earlier. Whilst $60 \%$ of respondents supported a complete ban on alcohol advertising, $41.8 \%$ of respondents believed that sponsorships by alcohol companies should be prohibited (18.5\% strongly agreeing and $23.3 \%$ agreeing), as illustrated in Figure 7.

Figure 7: Sponsorships by alcohol companies should be prohibited

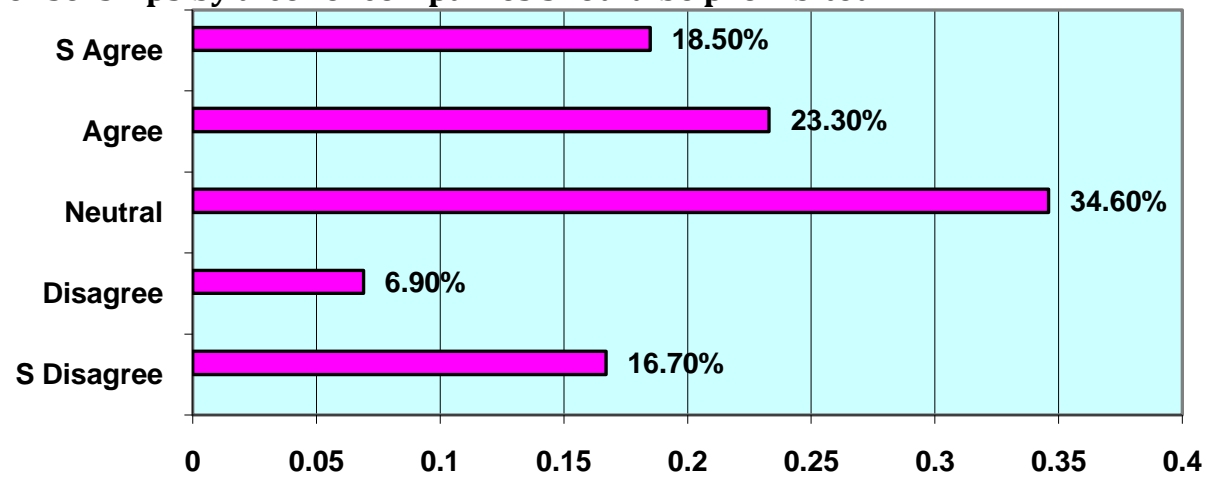

$34.6 \%$ of respondents were neutral in this regard and $23.6 \%$ of respondents supported the view that sponsorship by alcohol companies should not be prohibited.

Counter alcohol advertising should be introduced

As indicated in Figure 8, 74\% of respondents supported the introduction of counter-alcohol advertising (37\% agreeing and $37 \%$ strongly agreeing). $13.7 \%$ of respondents were in disagreement that counter alcohol advertising should be introduced. Counter-alcohol advertisements are usually produced by government health departments, alcohol producing companies and community forums (Agostinelli \& Grube, 2002).

Figure 8: Counter-alcohol advertising should be introduced

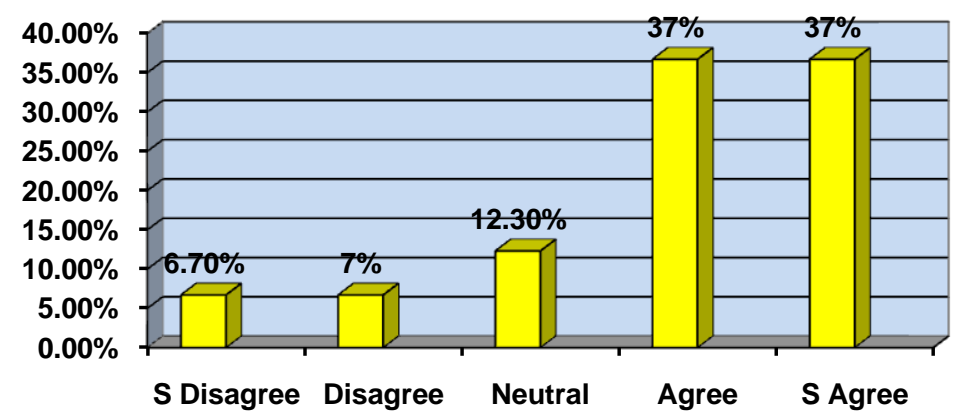


Mean values of the items: Table 2 presents the mean values of the eight items that were used to assess consumer attitudes towards alcohol advertising. The highest mean score of 4.37 pertained to excessive alcohol consumption being related to serious health issues. The second-highest mean score pertained to a support for counter alcohol advertising being introduced (3.91), followed by advertisements for alcohol influencing the people's view on alcohol positively (3.81). The lowest mean score (2.47) pertained to advertisements for alcohol influencing respondent's view on alcohol positively.

Table 2: Mean values- Attitude towards alcohol advertising

\begin{tabular}{lll}
\hline Item & Total & Mean \\
\hline Banning of alcohol advertising will reduce alcohol consumption & 390 & 2.66 \\
Alcohol advertisements influence non-drinkers to consume alcohol & 390 & 2.73 \\
Alcohol advertisements influence youth and adolescents to consume alcohol & 390 & 3.81 \\
Advertisements for alcohol influencing respondent's view on alcohol positively & 390 & 2.47 \\
Alcohol consumption resulting in serious health issues & 390 & 4.37 \\
Alcohol advertisements should be completely banned & 390 & 3.60 \\
Sponsorships by alcohol companies should be prohibited & 390 & 2.80 \\
Counter-alcohol advertising should be introduced & 390 & 3.91 \\
\hline
\end{tabular}

Relationship between the biographical variables and attitudes towards alcohol advertising: The results, as reflected in Table 3 indicate no significant relationship between gender and the items that assessed attitude towards alcohol advertising ( $>0.05$ in all instances). The hypothesis that there is no significant relationship between gender and attitude towards alcohol advertising is therefore accepted.

Table 3: Relationship between gender and attitude towards alcohol advertising

\begin{tabular}{lll}
\hline Item & $\mathbf{\chi 2}$ & $\mathbf{p}$ \\
\hline Banning of alcohol advertising will reduce alcohol consumption & 8.09 & 0.204 \\
Alcohol advertisements influence non-drinkers to consume alcohol & 4.59 & 0.273 \\
Alcohol advertisements influence youth and adolescents to consume alcohol & 3.89 & 0.634 \\
Advertisements for alcohol influencing respondent's view on alcohol positively & 1.71 & 0.715 \\
Alcohol consumption resulting in serious health issues & 1.38 & 0.532 \\
Alcohol advertisements should be completely banned & 2.2 & 0.193 \\
Sponsorships by alcohol companies should be prohibited & 4.73 & 0.409 \\
Counter-alcohol advertising should be introduced & 2.89 & 0.725 \\
\hline
\end{tabular}

As indicated in Table 4, it emerged that there was no significant relationship between age and each of the eight items that measured respondent attitude towards alcohol advertising ( $p>0.05)$. The hypothesis that there is no significant relationship between age and attitude towards alcohol advertising is therefore accepted.

Table 4: Relationship between age and attitude towards alcohol advertising

\begin{tabular}{llc}
\hline Item & $\mathbf{\chi 2}$ & $\mathbf{p}$ \\
\hline Banning of alcohol advertising will reduce alcohol consumption & 0.75 & 0.944 \\
Alcohol advertisements influence non-drinkers to consume alcohol & 5.61 & 0.230 \\
Alcohol advertisements influence youth and adolescents to consume alcohol & 3.72 & 0.466 \\
Advertisements for alcohol influencing respondent's view on alcohol positively & 4.25 & 0.374 \\
Alcohol consumption resulting in serious health issues & 2.52 & 0.641 \\
Alcohol advertisements should be completely banned & 2.41 & 0.514 \\
Sponsorships by alcohol companies should be prohibited & 3.23 & 0.661 \\
Counter-alcohol advertising should be introduced & 7.66 & 0.104 \\
\hline
\end{tabular}


The results, as reflected in Table 5 indicate no significant relationship between income and the items that assessed attitude towards alcohol advertising ( $p>0.05$ in all instances). The hypothesis that there is no significant relationship between income and attitude towards alcohol advertising is accepted.

Table 5: Relationship between income and attitude towards alcohol advertising

\begin{tabular}{llc}
\hline Item & $\chi \mathbf{2}$ & $\mathbf{p}$ \\
\hline Banning of alcohol advertising will reduce alcohol consumption & 1.39 & 0.249 \\
Alcohol advertisements influence non-drinkers to consume alcohol & 2.54 & 0.058 \\
Alcohol advertisements influence youth and adolescents to consume alcohol & 1.46 & 0.096 \\
Advertisements for alcohol influencing respondent's view on alcohol positively & 2.27 & 0.427 \\
Alcohol consumption resulting in serious health issues & 1.34 & 0.534 \\
Alcohol advertisements should be completely banned & 2.47 & 0.944 \\
Sponsorships by alcohol companies should be prohibited & 1.67 & 0.256 \\
Counter-alcohol advertising should be introduced & 2.27 & 0.741 \\
\hline
\end{tabular}

When assessing the relationship between education level and attitude towards alcohol advertising, it emerged that there was no significant relationship between education level and each of the eight items that measured respondent attitude towards alcohol advertising $(\mathrm{p}>0.05)$. This is reflected in Table 6. The hypothesis that there is no significant relationship between education level and attitude towards alcohol advertising is therefore accepted.

Table 6: Relationship between education level and attitude towards alcohol advertising

\begin{tabular}{llc}
\hline Item & \multirow{2}{*}{$\mathbf{p}$} \\
\hline Banning of alcohol advertising will reduce alcohol consumption & 3.81 & 0.404 \\
Alcohol advertisements influence non-drinkers to consume alcohol & 3.77 & 0.821 \\
Alcohol advertisements influence youth and adolescents to consume alcohol & 3.23 & 0.068 \\
Advertisements for alcohol influencing respondent's view on alcohol positively & 4.01 & 0.347 \\
Alcohol consumption resulting in serious health issues & 1.53 & 0.641 \\
Alcohol advertisements should be completely banned & 4.45 & 0.101 \\
Sponsorships by alcohol companies should be prohibited & 3.32 & 0.266 \\
Counter-alcohol advertising should be introduced & 2.55 & 0.234 \\
\hline
\end{tabular}

The results, as reflected in Table 7 indicate no significant relationship between race and the items that assessed attitudes towards alcohol advertising ( $p>0.05$ in all instances). The hypothesis that there is no significant relationship between race and attitude towards alcohol advertising is accepted.

Table 7: Relationship between education race and attitude towards alcohol advertising

\begin{tabular}{|c|c|c|}
\hline Item & $\chi^{2}$ & $\mathbf{P}$ \\
\hline Banning of alcohol advertising will reduce alcohol consumption & 2.84 & 0.204 \\
\hline Alcohol advertisements influence non-drinkers to consume alcohol & 3.21 & 0.521 \\
\hline Alcohol advertisements influence youth and adolescents to consume alcohol & 3.29 & 0.098 \\
\hline Advertisements for alcohol influencing respondent's view on alcohol positively & 4.07 & 0.437 \\
\hline Alcohol consumption resulting in serious health issues & 1.63 & 0.461 \\
\hline Alcohol advertisements should be completely banned & 4.65 & 0.105 \\
\hline Sponsorships by alcohol companies should be prohibited & 3.72 & 0.268 \\
\hline Counter-alcohol advertising should be introduced & 1.55 & 0.334 \\
\hline
\end{tabular}




\section{Conclusion and Recommendations}

It is clear that on the one hand, the South African government and (as evidenced by the empirical study) consumers are in support of the banning of alcohol advertising. On the other hand, other stakeholders, particularly the alcohol industry and the advertising industry have made a case for the status quo to remain. Should advertising for alcohol be continued to be permitted, more stringent regulations are likely to be put in place. These regulations will pertain to inter alia, specific media that may be used for alcohol advertisements, the content of advertisements and the warnings that must accompany alcohol advertising. The alcohol industry should consider other advertising channels, without breaching regulations. Utilizing alternative channels could address the long-term survival of the advertising industry and its stakeholders. To this end, digital marketing media, including social media will be a favored proposition. This will also address the issue of traditional media starting to lose their effectiveness. Social media has been known to benefit marketers by identifying new opportunities, creating new target markets, increasing brand awareness, creating a personal link with consumers and being relatively inexpensive. The alcohol industry can also display responsibility by making health warnings related to alcohol abuse more explicit in its advertisements. Given the negative effects created by alcohol misuse, in terms of its social and health consequences, it is inevitable that counteradvertising for alcohol will be on the increase. The various lobby groups in South Africa e.g. Arrive Alive, Alcoholics Anonymous and Community-based organizations are expected to place greater emphasis on counter-alcohol advertising. Clearly, there must be a balance between the rights of the alcohol companies to advertise their product and the need for society to understand the ramifications of alcohol misuse. This paper sought to assess consumer attitude towards the proposed banning of alcohol advertising in South Africa. Arguments for and against the advertising of alcohol were presented. The demographic profile of respondents was ascertained, specific aspects on attitudes towards the banning of alcohol advertising were examined and the relationship between the selected biographic variables and attitude towards the banning of alcohol advertising were determined. The results indicate no significant relationship between the selected demographic variables (viz. gender, age, income, education level and race) and attitude towards the advertising of alcohol.

\section{References}

Agostinelli, G. \& Grube, J. W. (2002). Alcohol counter-advertising and the media. Available at: http://pubs.niaa.nih.gov/publications/arh. [Accessed 24 January 2013].

Amen, U. (2011). Media influence on marketing communications. Interdisciplinary journal of contemporary research in business, 3(1), 1191-1216.

Anderson, P., de Bruijn, A., Angus, K., Gordon, R. \& Hastings, G. (2009). Impact of alcohol advertising and media exposure on adolescent alcohol use: a systematic view. Available at: http://dx.doi.org/10.1093/alcalc/agn115. [Accessed 30 January 2013].

Crotty, A. (2012). Drinks makers oppose ad ban. Available at: http://nu.org.za. [Accessed 31 January 2013].

Etzel, M. J., Walker, B. \& Stanton, W. (2007). Marketing Management. 14thed. New York: McGraw Hill.

Fin24. (2011). Alcohol ad ban will cost jobs - study. Available at: http://www.fin24.com/Economy [Accessed 24 January 2013].

Haw, P. (2011). Alcohol advertising: To ban or not to ban. Available at: http://www.leader.co.za/article.aspx?s [Accessed 20 February 2013].

Houser, J. (2008). Nursing Research: Reading, using and creating research. Denver: Jones \& Bartlett Publishers.

Institute of Alcohol Studies. (2007). Alcohol and Advertising. London: Institute of Alcohol Studies. Available at: http://www.ias.org.uk/resources/factsheets/advertising [Accessed 14 February 2013].

Jogender, M. (2008). Advertising, marketing and sales management. $1^{\text {st }}$ ed. Jaipur: Global Media.

Kotler, P. \& Armstrong, G. (2010). Principles of Marketing. 13 ${ }^{\text {th }}$ ed. New Jersey: Pearson Prentice Hall.

Lamb, C. W., Hair, J. F., McDaniel, C., Boschoff, C. \& Terblanche, N. S. (2008). Marketing. $3^{\text {rd }}$ ed. Cape Town: Oxford University Press.

Moerdyk, C. (2011). Impact assessment of a ban on alcohol advertising. Available at: http://www.bizcommuniyu.com [Accessed 21 February 2013].

McDaniel, C., Lamb, C. W. \& Hair, J. F. (2012). Marketing Essentials. Mason, Ohio: South Western-Cengage Learning. 
Ukwazi, N. (2012). Why I support banning alcohol advertising or Stopping SAB and Africa's Lusty, Lively, Exploitation Since 1652. Available at: http://nu.org.za. [Accessed 31 January 2013].

Parry, C., Burnhams, N. H. \& London, L. (2012). A total ban on alcohol advertising: Presenting the public health case. South African Medical Journal, 102(7).

Peer, N., Bradshaw, D., Laubsher, R. \& Steyn, K. (2009). Trends in adult tobacco use from two South African demographic and health surveys conducted in 1998 and 2003. South African Medical Journal, 99, 744749.

Ringold, D. J. (2008). Responsibility and brand advertising in the alcoholic beverages market: The modeling of normative drinking behavior. Journal of Advertising, 37(1), 127-141.

Ross, K. (2009). Expert advises SA to consider ban on alcohol advertising. Cape Times, 14 Sept. Available at: http://www.search.proquest.com.dutlib.dut.ac.za [Accessed 14 February 2013].

Sekaran, U. (2003). Research Methods for Business - A skill building approach. $4^{\text {th }}$ edition. Hoboken, NJ: John Wiley \& Sons, Inc.

Schifman, L. G., Kanuk, L. L. \& Wisenbilt, J. (2010). Consumer Behavior. 10 $0^{\text {th }}$ ed. New Jersey: Pearson.

Shimp, T. A. (2010). Integrated Marketing Communication in Advertising and Promotion, $8^{\text {the }}$. Mason, Ohio: South Western-Cengage Learning.

The Economist (2012). International: Don't touch a drop; South Africa and alcohol, Jan.7. Available at: http://search.proquest.com.dutlib.dut.ac.za [Accessed 4 February 2013].

Welman, J. C., Kruger, S. J. \& Mitchell, L. (2009). Research Methodology. $2^{\text {nd }}$ ed. Cape Town: Oxford University Press. 